panying commentaries are in 'News and Views' style and are in general scholarly, with a dash of humour, clearly rivalling those of its parent. As a result of all this, Nature Genetics is one of a handful of journals whose monthly arrival I now eagerly await.

Human Molecular Genetics is a spin-off of Nucleic Acids Research. Both it and the third new journal, Human Mutation, have distinguished, international editorial boards. In both cases, the editors have accomplished what they set out to do: to provide a reputable journal devoted to publishing papers describing the genetic analysis of human hereditary diseases. The journals are true to their names, and Human Molecular Genetics thereby has a wider scope, with most of its articles dealing with basic studies of gene expression, physical mapping and linkage related to human genes of interest. The quality and content of these articles are in general what one would expect from a top-notch speciality journal. Human Molecular Genetics has so far attracted a more interesting and varied collection of papers than Human Mutation. Almost all the papers in Human Mutation, and about a quarter of those in Human Molecular Genetics, report additional examples of mutations in diseases already described at the genetic level. Although a bit archival (the molecular equivalent of clinical case reports), such papers can be useful to investigators studying the disease and have obvious clinical importance. Documentation of the mutations is usually robust and a subset of the papers reports useful technical modifications that have aided the identification of mutations and that occasionally have general applicability. Each of these two journals has a special feature. Nearly every issue of Human Mutation carries a brief review of mutations in a specific gene; these reviews are well written, concise and up to date. Human Molecular Genetics has a section devoted to the description of new, highly polymorphic markers, and currently provides the best vehicle for publishing (and finding) such polymorphisms in the literature.

In summary, each of the three journals provides authors and readers with a valuable resource for a variety of studies relevant to human genetic disease. Human Molecular Genetics and Human Mutation deserve to be in every library catering to a community of human geneticists. Nature Genetics has broader appeal, lying squarely at the interface between molecular biology, genetics and medicine; many will find a personal subscription rewarding.

Bert Vogelstein is in the Molecular Genetics Laboratory, Johns Hopkins Oncology Center, 424 North Bond Street, Baltimore, Maryland 21231, USA.

\section{Journals index}

Acta Polymerica

Advanced Materials for Optics and Electronics

Advances in Neuroimmunology

Antisense Research and

Development

Applicable Algebra in Engineering,

Communication and Computing

Applied Intelligence

Basic and Applied Myology

Biological Signals

BioMetals

Cell Transplantation

Current Directions in

Psychological Science

Down to Earth

Earth

Ecological Engineering Journal of Ecotechnology

Environmental Values

Evolutionary Anthropology

Exploration and Mining Geology

Fish and Shellfish Immunology

Fisheries Oceanography

Helix

Human Molecular Genetics

Immunology and Infectious Diseases

Infectious Agents and Disease

International Journal of

Nonlinear Optical Physics

International Journal of

Osteoarchaeology
Development Dynamics

Human Mutation
583

583

572

577

585

584

572

573

582

577

575

574

588

587

586

587

579

586

576

576

570

569

569

571

571

585

579
Journal of Fluorescence Journal of Genetic Counseling

Journal of Hematotherapy

Journal of Liposome Research

Journal of Logic and Computation

Journal of Mathematical

Imaging and Vision

Journal of Sleep Research

Materials World

Mediators of Inflammation

Microbial Releases

Molecular Ecology

Molecular Engineering

Molecular Marine Biology and

Biotechnology

Molecular Materials

Natural Product Letters

Natural Toxins

Nature Genetics

Neuromuscular Disorders

Parallel Processing Letters

Pharmaceutical and

Pharmacological Letters

Pharmacology Communications

Probe

Public Understanding of Science

Solid State Nuclear Magnetic

Resonance

Stem Cells

The International Journal for

the Psychology of Religion

The International Journal on

Artifical Intelligence Tools

Vaccine Research

Vegetation History and

Archaeobotany
573

571

578

577

585

584

575

582

574

580

578

583

576

583

581

580

569

572

585

573

573

588

589

581

\section{The acceptable face of science?}

\section{Walter Gratzer}

Helix: Amgen's Magazine of Biotechnology. Editor James Geary. 3/yr. Bugamor International, Haak 58, 1353 AE Almere-Haven, The Netherlands. Distribution details available on application to publisher.

HERE is a good deed in a naughty world, a new journal that no one can deplore, a source for once of pleasure and not of pain. Imagine having to think up a name for a new biotechnology company - the more euphonious variants on the Biogen, Genentech, Celltech theme, even including (in Italy) Genitalia, being surely now more or less exhausted - let alone a new journal. Cell and Gene have gone, not to mention Brain, Blood, Gut and Bone. The surface scientists had an imaginative breakthrough with Langmuir, so perhaps we may soon see volume 1 of Crick, Watson or Pauling (Linus even?) hit the library shelves.

Well, Amgen (a leader in the biotechnology stakes) has come up with Helix, surprisingly hitherto overlooked in the scramble for numinous titles, and a felicitous choice. For the helix is surely a potent symbol for our time. Salvador Dali, who represented one in a painting, believed that he had prefigured the discovery of the Thread of Life. The mediaeval divine, Origen, taught that since the sphere was the most perfect of all objects, all points on its surface being equidistant from the centre, the virtuous among us would, come the Day of Judgement, be transformed into spheres and enter paradise rolling. Perhaps, then, a trendier theology will have us changed into helices - so much richer in symmetry and imagery - to enter paradise screwing.

Only in the third issue of Helix is there actually a dissertation on the helix and its place in nature and in architecture, agreeably written by John Galloway and captivatingly illustrated. The graphics and the photographs, many of them light- and electron-microscope images in false colour, are superlative throughout and the production of Helix has an aesthetic panache that makes it a rare pleasure to turn the pages. There is clearly here a vision of science as art and I hope the journal will reach a wider public than the biological community alone. The name of Amgen appears in small print on the cover and there is nothing in the text in any of the issues that so much as hints at promotion. The scientific articles reach out to the nonspecialist and are at about the level of Scientific American. The best are excel- 
lent; H. Schellekens on mitochondrial DNA and P. K. Vogt on oncogenes are two examples that I found crisp and illuminating. There are also interviews with important personages - Nobel laureates, journal editors and the like. This is a difficult genre, and here (at least to my mind) only moderately successful, for there are too few surprising revelations and no outrageous opinions are ventilated. Book reviews too suffer from a certain decorum (does Gallo have to be treated with quite such servility?). A few errors have slipped through undetected: Chaim Weizmann, for instance, should not have been allowed to pass as a colleague of Pasteur's.

But it is ungrateful to cavil where there is so much to enjoy. There are rewarding pieces by experts on such topics as the great medical illustrators, on alchemy, Taoist physiology, Vesalius, Willem de Kooning and Frank Lloyd Wright. The distinguished author of the last - not a scientist - does not remark on the helical fine-structure of the Guggenheim Museum in New York, prominently on view in two sumptuous photographs. Wright, incidentally, also had something to say on clinical science: doctors, he observed, can always bury their mistakes, but an architect can only advise his clients to plant vines.

It remains only to ask Amgen how they will select the lucky recipients of their covetable confection. Beg a subscription if you can!

Walter Gratzer is in the MRC Muscle and Cell Motility Unit, King's College London, 26-29 Drury Lane, London WC2B 5RL, UK.

\section{Powerful}

\section{knowledge}

\section{Susan Michie}

Journal of Genetic Counseling. Editorin-chief Deborah L. Eunpu. Human Sciences. 4/yr. USA \$95, elsewhere $\$ 100$ (institutional); USA $\$ 40$, elsewhere $\$ 45$ (personal).

As the work of the Human Genome Project continues, technology is being rapidly developed for an increasing range of screening and diagnostic tests for genetic diseases and conditions in individuals and their families, present and future.

Many questions are raised. How should the tests be presented? How should the uncertainty of risk be conveyed? How can the distress associated with 'positive results' be minimized? How are genetics and inheritance best explained? What is an 'informed decision'? What should family members be told?
There is a great need for such questions to be studied empirically and for results to be communicated to those providing, and purchasing, genetics services. The appearance last year of Journal of Genetic Counseling is therefore to be welcomed. This publication aims to provide genetic counsellors and other genetics advisers with "careful examination of the methods used to convey genetic information". It does so by peer-reviewed research, essays, review articles and letters.

A variety of issues are covered, such as the role of genetic counsellors in different services, cultural barriers to genetic ser-

vices and how to overcome them, and practical recommendations for counselling. So far, issues have contained papers that tend to discuss questions rather than provide data for addressing them. The all-American editorial board perhaps accounts for the lack of contributions from outside the United States. But the journal is a promising beginning in an area with great potential.

Susan Michie is in the Psychology and Genetics Research Group, United Medical and Dental Schools, Guy's Campus, London SE1 9RT, UK.

\section{In the footsteps of Pasteur}

\section{F. E. G. Cox}

Immunology and Infectious Diseases. Editor R. K. Chandra. Rapid Communications of Oxiord. 4/yr. £235, \$395 (institutional); $£ 82, \$ 140$ (personal).

Vaccine Research. Editor Michael G. Hanna Jr. Liebert. 4/yr. USA and Canada $\$ 149$, elsewhere $\$ 189$.

Infectious Agents and Disease. Editorin-chief Bernard Roizman. Raven. 6/yr. USA and Canada $\$ 138$, elsewhere $\$ 171$ (institutional); USA and Canada \$98, elsewhere $\$ 119$ (personal).

THERE is obviously a lot of immunological research being done and lots of journals in which the results can be published, so any new venture must fill an important and distinct niche; otherwise it merely becomes a dumping ground for the ephemera of the subject.

The present massive field of immunology originally grew out of studies on immunity to infection but, apart from Immunity and Infection and Vaccine, there are few journals dedicated to this area. So there does seem to be a niche for one or more new publications. Immunology and Infectious Diseases starts off with a very wide brief to publish original articles, clinical trials, brief communications, critical reviews and hypotheses on topics such as immunoregulation, immunocompetent cells, cytokines, cancer and autoimmune disease; in other words, much of the same as one might find in any one of a hundred publications. In fact, the range of the 50 or so articles published each year is immense, but few, if any, seem to be in the front line of immunological research. What is new, however, is the aim to publish papers within 12 weeks of acceptance, an ambition achieved a few times in the first issue but seldom since, with the publication time drifting more recently to an average of 10 months, and in one case 18 months. In summary, this is just another general immunological journal.
Vaccine Research "provides a central forum of documentation of basic and applied research in vaccine development and application" and publishes reviews, articles, reports, brief communications, letters and leading articles. Vaccines are becoming increasingly important and a journal such as this could be a welcome addition to the literature, especially if

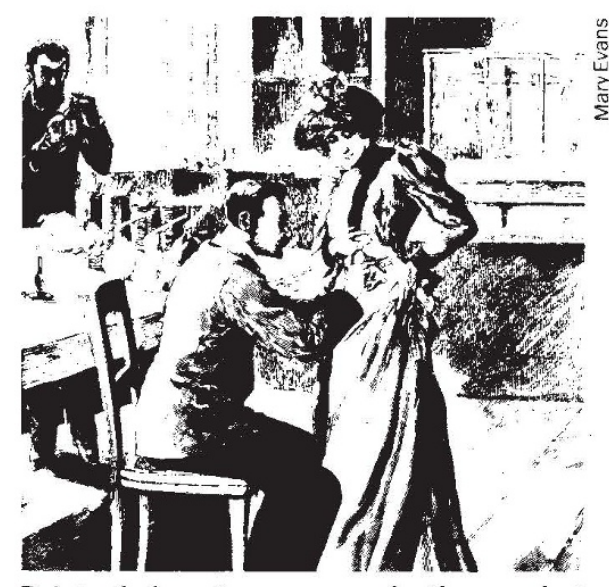

Point of departure - vaccination against cholera. From La Science Illustrée (c. 1890).

it covers veterinary topics. There are some good reviews but, in the main, the contents consist of five or six fairly ordinary papers mainly on experimental aspects of immunogenicity. Part 3 of volume 1 is devoted to the proceedings of a meeting on mucosal immunity and AIDS, and contains very little about vaccines. One doesn't get much for one's money because of the lavish use of space: 20 references occupy a whole page, for example. There is little evidence so far that Vaccine Research is going to be anything more than of peripheral interest to those working in the mainstream of this subject, although the occasional review might be well worth reading.

Two down and one to go. Infectious Agents and Disease, subtitled Reviews Issues and Commentary, publishes 